\title{
El mandato de toma de conciencia en la Convención Internacional sobre los Derechos de las Personas con Discapacidad frente a los estereotipos interseccionales en medios de comunicación sobre mujeres con discapacidad ${ }^{(*)(*)}$
}

\author{
The awareness mandate of the Convention on the Rights of Persons with \\ Disabilities as against intersectional stereotypes in the media on women \\ with disabilities
}

\author{
Renata Anahí Bregaglio Lazarte ${ }^{(* *)}$ \\ Perú - Pontificia Universidad Católica del Perú \\ Valquiria Ramos Obregón ${ }^{(+k+k)}$ \\ Perú - Pontifica Universidad Católica del Perú \\ Renato Antonio Constantino Caycho ${ }^{(+\infty+\infty)}$ \\ Perú - Pontificia Universidad Católica del Perú \\ Cristina Verano Calero( ${ }^{(* \star * \star *)}$ \\ Perú - Pontifica Universidad Católica del Perú
}

\begin{abstract}
Resumen: El presente trabajo identifica los vínculos entre la representación mediática de las mujeres con discapacidad y la situación de discriminación que enfrentan, a la luz de la Convención sobre los Derechos de las Personas con Discapacidad. El trabajo reconoce las formas de discriminación interseccional que enfrenta este colectivo; por ello, plantea que a partir de una lectura conjunta de la Convención sobre los Derechos de las Personas con Discapacidad y la Convención para Eliminar todas las Formas de Discriminación contra la Mujer se deriva la obligación de los Estados de prevenir la
\end{abstract}

$\left.{ }^{*}\right) \quad$ Nota del editor: este artículo fue recibido el 20 de octubre de 2019 y su publicación fue aprobada el 10 de noviembre de 2019.

$\left({ }^{* *} \quad\right.$ Algunas secciones de este texto están basadas en una investigación previa realizada para la Fraternidad Cristiana de Personas Enfermas y con Discapacidad del Perú con financiamiento de la Confederación Española de Personas con Discapacidad Física y Orgánica (COCEMFE), por los autores: Constantino Caycho, Renato; Ramos Obregón, Valquiria; Bregaglio Lazarte, Renata; Verano, Cristina. (2018). Voces en off: La representación mediática de las mujeres con discapacidad en medios periodísticos impresos de Lima y Huancayo.

${ }^{* * *}$ Docente asociada del Departamento Académico de Derecho de la Pontificia Universidad Católica del Perú. Magíster en Derechos Humanos por dicha casa de estudios y Máster en Derechos Fundamentales por la Universidad Carlos III de Madrid. Coordinadora del Grupo Interdisciplinario en Discapacidad de la Pontificia Universidad Católica del Perú - GRIDIS. Correo electrónico: renata. bregaglio@pucp.pe

$\left(^{* * *}\right)$ Licenciada en Periodismo por la Pontificia Universidad Católica del Perú (PUCP). Miembro del Grupo Interdisciplinario de Investigación en Discapacidad de la PUCP (GRIDIS) y exestudiante de la Clínica Jurídica en Discapacidad y Derechos Humanos. Actualmente es consultora en comunicaciones y jefa de prácticas del curso "Periodismo y Coyuntura" en la Facultad de Ciencias y Artes de la Comunicación de la PUCP. Correo electrónico: valquiria.ramos@pucp.pe

${ }^{(* * * *)}$ Docente del Departamento de Derecho de la Pontificia Universidad Católica del Perú. Abogado y magíster en Derechos Humanos por la misma casa de estudios. Máster en International Legal Studies del Washington College of Law de American University. Investigador del Grupo Interdisciplinario en Discapacidad de la PUCP - GRIDIS. Correo electrónico: renato.constantino@pucp.pe

$\left.{ }^{(* \star \star \star \star *}\right)$ Bachillera en Derecho por la Pontificia Universidad Católica del Perú. Miembro del Grupo Interdisciplinario de Investigación en Discapacidad de la PUCP - GRIDIS y asistente de la Clínica Jurídica en Discapacidad y Derechos Humanos. Interés en temas de derechos humanos, derechos de las personas con discapacidad y derechos de la mujer. Correo electrónico: c.verano@pucp.pe 
El mandato de toma de conciencia en la Convención Internacional sobre los Derechos de las Personas con Discapacidad frente a los estereotipos interseccionales en medios de comunicación sobre mujeres con discapacidad

The awareness mandate of the Convention on the Rights of Persons with Disabilities as against intersectional stereotypes in the media on women with disabilities

perpetuación de estereotipos sobre el género y la discapacidad a través de medios de comunicación. A partir de un análisis de la representación en medios, la investigación demuestra que actualmente, los medios de comunicación replican estereotipos falsos o proteccionistas las mujeres con discapacidad. En consecuencia, la investigación recomienda que un ejercicio responsable de la comunicación social debe (i) reflejar las demandas de accesibilidad de la población con discapacidad, (ii) resaltar el impacto positivo de entornos inclusivos, (iii) incluir a actrices, actores y role models con discapacidad en la publicidad y (iv) atender a los intereses de las audiencias con discapacidad.

Palabras clave: Mujeres con Discapacidad - Medios de Comunicación - Estereotipos - Toma de Conciencia Interseccionalidad - Derecho Internacional Público.

Abstract: This paper highlights the connections between representations of women with disabilities in mass media and the discrimination they face, in light of the State obligations derived from the Convention on the Rights of Persons with Disabilities (CRPD). The paper recognizes that this group faces intersectional forms of discrimination; because of this, the authors propose that a State obligation to prevent the perpetuation of stereotypes on gender and disability in mass media can be derived from a joint reading of CRPD and the Convention to Eliminate Discrimination Against Women. By analyzing representation in mass media, this paper finds that media outlets tend to convey false or protectionist stereotypes of women with disabilities. In consequence, the authors propose that responsible exercise of media-related professions should (i) reflect persons with disabilities' demands for accessibility, (ii) highlight the positive impact of inclusive environments, (iii) include actors, actresses and role models with disabilities in advertisement and (iv) respond to the interests of persons with disabilities as consumers of their content.

Keywords: Women with Disabilities - Media - Stereotypes Awareness - Intersectionality - Public International Law.

\section{Introducción}

El colectivo de mujeres con discapacidad es uno de los más discriminados a nivel mundial. Ellas se enfrentan a barreras de diversa índole: sociales, jurídicas, arquitectónicas y actitudinales (Comité sobre los Derechos de las Personas con Discapacidad, 2012a, párr. 3). Al igual que el resto de mujeres, se les exige cumplir con ciertas expectativas sociales y roles de género como la reproducción, la crianza, las labores de cuidado y el ser "bellas", pero se pone en cuestión su capacidad para cumplirlos a causa de sus deficiencias, otorgándoles una valoración social aún menor e impactando negativamente en su autoimagen personal (Mogollón, 2004, pág. 157; Domínguez, 2011).

Uno de los factores que contribuyen a esta situación es la representación mediática de las mujeres con discapacidad, pues los medios son uno de los principales espacios de socialización, construcción de identidades e intercambio social de estereotipos (Mancini, 2014; Bernárdez, 2015). Su impacto es aún mayor cuando se tiene en cuenta que la participación ciudadana de estas mujeres es aún escasa, dado que las pocas que logran intervenir en el debate público se convierten en el único referente para ejercer la vocería de este colectivo(1).

Con esto en mente, el presente artículo busca determinar cuáles son las obligaciones que surgen para el Estado y la sociedad con respecto a la representación mediática de las personas con discapacidad. Dichas obligaciones parten, principalmente, de la obligación de toma de conciencia que se encuentra en el artículo 8 de la Convención sobre los Derechos de las Personas con Discapacidad (CDPD) ${ }^{(2)}$ y sobre el artículo 5 de la Convención para la Eliminación de toda forma de Discriminación contra la Mujer (CEDAW) ${ }^{(3)}$ referido a la eliminación de estereotipos.

\section{La intersección de discapacidad y género como una forma distinta de discriminación}

Las mujeres con discapacidad enfrentan diferentes barreras sociales debido a la confluencia de dos de sus condiciones: la de género y la de discapacidad. Estas condiciones pueden interactuar generando nuevas y diferentes formas de discriminación.

(1) Sobre este punto, en Perú, vale la pena resaltar que en el periodo parlamentario 2011 - 2016 hubo cinco congresistas varones con discapacidad: Michael Urtecho, Javier Diez Canseco, Giancarlo Vachelli, John Reynaga y Luis Galarreta. Este último fue reelecto para el siguiente periodo. Ni en ese periodo ni en el siguiente hubo mujeres con discapacidad que hayan sido congresistas.

(2) La Convención sobre los Derechos de la Personas con Discapacidad entró en vigor para el Perú en el año 2008.

(3) La Convención para la Eliminación de toda forma de Discriminación contra la Mujer entró en vigor para el Perú en año 1982. 
2.1. La interseccionalidad como forma de discriminación Las situaciones de discriminación, en tanto contextuales, pueden verse alteradas o potenciadas cuando dos o más de ellas se presentan en una persona. A esto se le conoce como interseccionalidad. Este concepto fue originalmente desarrollado por Kimberlé Crenshaw, quien lo postuló a partir de la interacción que el sexismo y el racismo podían provocar en las mujeres afrodescendientes en Estados Unidos (Crenshaw, 1991, pág. 1242). La discriminación interseccional, así, se entiende como la convergencia estructural de variables, que coloca a las personas en una situación de subordinación específica que trasciende a la suma de sus situaciones de opresión por variables individuales (Crenshaw, 1991, pág. 1246), y a través de su análisis se busca plantear que las situaciones de exclusión que enfrentan las mujeres con discapacidad no son las mismas que el resto de mujeres. Este encuentro de diversas causas de discriminación es simultáneo (Aylward, 2010, pág. 17) y "crea consecuencias para los afectados en formas que son diferentes por las consecuencias sufridas por aquellos que son objeto de solo una forma de discriminación" (Coomaraswamy, 2001, párr. 20).

Desde el Derecho, la discriminación interseccional se produce cuando a una persona, por el hecho de poseer dos o más características que coinciden con los motivos prohibidos de discriminación, se le restringe el ejercicio de derechos. Estos interactúan al mismo tiempo de forma inseparable (Comité para la Eliminación de la Discriminación contra la Mujer, 2010, párr. 18; Comité sobre los Derechos de las Personas con Discapacidad, 2016a, párr. 4). Este concepto "reconoce que las personas no sufren discriminación como miembros de un grupo homogéneo, sino como individuos con identidades, condiciones y circunstancias vitales multidimensionales" (Comité sobre los Derechos de las Personas con Discapacidad, 2016a, párr. 16). Así, la discriminación y sus consecuencias son analizadas a raíz de dichos cruces, lo cual permite establecer el impacto de dicha convergencia en distintas situaciones.

\subsection{Las mujeres con discapacidad y la discriminación interseccional que enfrentan}

Las mujeres y las personas con discapacidad han sido tradicionalmente excluidos (Cruz, 2013, pág. 51-52). En el caso de las mujeres, si bien han sido sistemáticamente víctimas de violencia ${ }^{(4)}$, esta ha sido socialmente aceptada hasta hace poco por encontrarse circunscrita fundamentalmente al ámbito privado (Nieves, 1996, pág. 8). Incluso, en el marco jurídico internacional de los derechos humanos, al reconocer todas las violaciones a los derechos humanos que son de gravedad indudable (como el genocidio, la esclavitud, entre otros), se omitió incluir dentro de la construcción de estas vulneraciones y violaciones específicas contra mujeres (Charlesworth y Chinkin, 2017, pág. 9).

Por otro lado, a lo largo de la historia, las personas con discapacidad han sido excluidas de la sociedad e impedidas de ejercer sus derechos por considerarse seres inferiores (Barton, 2009, pág. 129). Durante la Antigüedad y Edad Media, bajo lo que se conoce como el modelo de la prescindencia, se creía que las personas con discapacidad no tenían nada que aportar a la comunidad, por lo que se podía, justamente, prescindir de ellas. A inicios del siglo veinte, comenzó a imperar un modelo médico de la discapacidad, bajo el cual esta era un problema que debía ser curado a fin de normalizar a la persona para integrarla en la sociedad (Cuenca, 2012; Palacios, 2008, pág. 68; Barnes y Oliver, 2012). Hoy en día, a pesar de que el modelo epistemológico vigente señala que toda persona con discapacidad es sujeto de derechos, y que la discapacidad es un concepto social, la aplicación de los modelos surgidos en la primera etapa de la historia (modelo de prescindencia) y en la segunda (modelo médico) se mantienen vigentes (Comité sobre los derechos de las Personas con Discapacidad, 2018, párr. 2).

Producto de la combinación de ambas identidades, se ha generado un mayor grado de vulnerabilidad, sobre todo tomando en cuenta que el grupo "mujeres" no es un grupo homogéneo (Ministerio de la Mujer y Poblaciones Vulnerables, 2016, pág. 16), así como tampoco lo es el grupo "personas con discapacidad". Estas múltiples e interseccionales formas de discriminación contra las mujeres y niñas con discapacidad se han materializado en particular en relación con "la igualdad de acceso a la educación, las oportunidades económicas, la interacción social y la justicia; el igual reconocimiento ante la ley; y la capacidad de participar en la política y ejercer control de sus propias

(4) Como lo señaló la Corte Interamericana de Derechos Humanos (Corte IDH) desde el Caso del Penal Miguel Castro Castro vs. Perú (2006, párr. 206) hasta el reciente Caso Mujeres Víctimas de Tortura Sexual en Atenco vs. México (2018, párr. 211), las mujeres son afectadas por los actos de violencia de manera diferenciada en relación con los hombres, ya que ciertos actos de violencestán dirigidos específicamente a ellas, como la violencia sexual. 
El mandato de toma de conciencia en la Convención Internacional sobre los Derechos de las Personas con Discapacidad frente a los estereotipos interseccionales en medios de comunicación sobre mujeres con discapacidad

The awareness mandate of the Convention on the Rights of Persons with Disabilities as against intersectional stereotypes in the media on women with disabilities

vidas en diversos contextos" (Comité sobre los Derechos de las Personas con Discapacidad, 2016a, párr. 2).

La CDPD identificó esta problemática y planteó un artículo específico sobre las barreras que enfrentan las mujeres con discapacidad, que, a decir del Comité sobre los Derechos de las Personas con Discapacidad (Comité PCD), es "una respuesta a la falta de reconocimiento de los derechos de las mujeres y las niñas con discapacidad" (2016a, párr. 7). Dicho artículo señala:

\section{"Artículo 6. Mujeres con Discapacidad.}

1. Los Estados Partes reconocen que las mujeres y las niñas con discapacidad están sujetas a múltiples formas de discriminación y que, a ese respecto, deben adoptar medidas para asegurar que puedan disfrutar plenamente y en condiciones de igualdad de todos los derechos humanos y libertades fundamentales.

2. Los Estados Partes tomarán todas las medidas pertinentes para asegurar el pleno desarrollo, adelanto y potenciación de la mujer, con el propósito de garantizarle el ejercicio y disfrute de los derechos humanos y las libertades fundamentales establecidos en la presente Convención" (2008).

Este artículo, de acuerdo con el Comité PCD, era y sigue siendo necesario en un contexto en el que las mujeres y niñas con discapacidad: (i) "tienen más probabilidades de ser objeto de discriminación que los hombres y los niños con discapacidad, y que las mujeres y las niñas sin discapacidad" (Comité PCD, 2016a, párr. 9) y; (ii) "tienden a ser menos conscientes de sus derechos y de los medios disponibles para hacerlos valer" (Alto Comisionado de las Naciones Unidas para los Derechos Humanos 2012, párr. 40).

Además, el artículo 6 de la CDPD hace un llamado a los Estados Partes para que implementen medidas orientadas "al desarrollo, el adelanto y la potenciación de las mujeres y las niñas con discapacidad", tomando como punto de partida su opinión y el reconocimiento de su titularidad de derechos (Comité sobre los Derechos de las Personas con Discapacidad, 2016a, párr. 7). En consonancia, la meta 5.5 de los Objetivos del Desarrollo Sostenible a 2030 es "asegurar la participación plena y efectiva de las mujeres y la igualdad de oportunidades de liderazgo a todos los niveles decisorios en la vida política, económica y pública". En la misma línea, la meta 5.1 establece la necesidad de "poner fin a todas las formas de discriminación contra todas las mujeres y las niñas en todo el mundo" (Organización de las Naciones Unidas, 2015).

De manera previa a la CDPD, la Convención Interamericana para prevenir, sancionar y erradicar la violencia contra la mujer, Convención de Belém Do Pará, había ya identificado lo siguiente:(5)

\begin{abstract}
"Artículo 9
(...) los Estados Partes tendrán especialmente en cuenta la situación de vulnerabilidad a la violencia que pueda sufrir la mujer en razón, entre otras, de su raza o de su condición étnica, de migrante, refugiada o desplazada. En igual sentido se considerará a la mujer que es objeto de violencia cuando está embarazada, es discapacitada, menor de edad, anciana, o está en situación socioeconómica desfavorable o afectada por situaciones de conflictos armados o de privación de su libertad".
\end{abstract}

Precisamente, una de las situaciones que más se presenta y afecta gravemente los derechos de mujeres y niñas con discapacidad es el de la violencia contra este colectivo. De acuerdo con un informe presentado al Parlamento Europeo, aproximadamente el $80 \%$ de las mujeres con discapacidad ha sufrido violencia y tiene una probabilidad cuatro veces mayor que el resto de mujeres de ser víctima de violencia sexual (Valenciano 2004, pág. 14). En el Perú, los Centros de Emergencia Mujer (CEM) del Ministerio de la Mujer y Poblaciones Vulnerables (MIMP) reportan que en los últimos años se ha atendido cada vez más casos de violencia contra este colectivo. En el año 2016 se registraron 1032 casos; en 2017, 1435 casos; en 2018, 1073 casos (MIMP, 2019).

Ahora, los actos de violencia contra mujeres con discapacidad incluyen otras formas de violencia física y psicológica de abandono. Entre estas formas podemos destacar la esterilización forzada, la agresión verbal, la ridiculización, la supresión de rampas o dispositivos de movilidad personal o de comunicación, la denegación de asistencia personal para actividades de la vida diaria, entre otras (Alto Comisionado de las Naciones Unidas para los Derechos Humanos, 2012, párr. 22).

Frente a esta realidad, es necesario dar un enfoque interseccional en el análisis de la discriminación a mujeres con discapacidad, pues ello no presupone "encasillar a las personas en categorías rígidas para reivindicarlas", sino que busca "entrecruzar

(5) La Corte IDH, en el caso Penal Miguel Castro Castro vs. Perú (2006, párr. 276), ha reconocido que este tratado forma parte del corpus juris internacional en materia de protección de la integridad personal de las mujeres. El Estado peruano ratificó la Convención Interamericana para prevenir, sancionar y erradicar la violencia contra la mujer "Convención Belém Do Para" el 01 de octubre de 1996. 
las categorías de identidad" (Zambrano y Uchuypoma, 2015, pág. 24). El propio Comité para la Eliminación de la Discriminación contra la mujer (Comité CEDAW) ha reconocido que la discriminación basada en el sexo y el género está indisolublemente vinculada a estos otros factores (2010, párr. 18), como la discapacidad. En esa línea, en su Recomendación General 35 sobre la violencia por razón de género contra la mujer, señaló que los Estados Partes deben asegurar mecanismos de protección adecuados y accesibles para evitar posibles actos de violencia (Comité CEDAW, 2017, párr. 31). En el caso de víctimas con discapacidad, a decir del propio Comité CEDAW, esto incluye la eliminación de barreras comunicacionales (2017, párr. 31). De igual manera, el Comité PCD, en su Observación General 3, abordó la situación de mujeres y niñas con discapacidad. Allí puso en evidencia las distintas barreras a las que se enfrentan las mujeres y niñas durante gran parte de su vida y que crean situaciones de discriminación interseccional (2016, párr. 17).

\section{Toma de conciencia, estereotipos y discriminación}

Un aspecto que sin duda contribuye a la discriminación, y, en específico, a la que sufren las mujeres con discapacidad, es la proliferación de estereotipos. Los estereotipos son categorías de atributos específicos de un grupo social (Jiménez \& Aguado, 2002), son imágenes o representaciones permanentes que reflejan la percepción generalizada de algo o alguien según un determinado colectivo o grupo de personas. La configuración de los mismos depende de un proceso de selección, categorización y generalización en el que se hace énfasis en algunos atributos en detrimento de otros (Gamarnik, 2009, pág. 1). Tal percepción puede esconder juicios de valor históricos contra un grupo específico de personas; por ello, según Gamarnik, "la fuerza del estereotipo se mide en relación directa con el grado en que este es percibido como representación válida de la realidad" (2009, pág. 1). A través del estereotipo, se reducen las varias dimensiones de la personalidad de una persona, quien será vista únicamente por dicha visión estereotipada (Cook y Cusack, 2010, pág. 11). Por esa razón, al ser repetidos constantemente y compartidos por la sociedad, se naturalizan.

La dinámica descrita ocasiona que ciertos grupos sociales encuentren en los estereotipos la justificación perfecta para desarrollar conductas de discriminación. Así, los estereotipos permean el sistema jurídico y se consagran en las normas y en las decisiones de los operadores jurídicos. A su vez, las conductas discriminatorias en perjuicio de la persona que sufre la estigmatización perpetúan la situación de exclusión social y vulneración de derechos (Comité PCD 2016a, párr. 37).

Ejemplo de ello es la situación que resolvió, en 2014, el Comité CEDAW en el caso R.P.B contra Filipinas, relativo al proceso por violencia sexual enfrentado por una mujer sorda. En dicho caso, el Comité CEDAW señaló que el proceso penal estuvo plagado de estereotipos, los cuales llevaron a que el derecho de acceso a la justicia de la mujer víctima se viera vulnerado. Así, la jurisdicción interna desestimó el caso de violencia sexual argumentando que la víctima no se había resistido y utilizó el hecho de que no haya gritado como parte de dicha argumentación. En su decisión, el Comité CEDAW estableció que, en las decisiones judiciales, se debía atender "a las cuestiones de género, edad y discapacidad" (2014, párr. 8.8 y 8.9), como parte del deber de eliminación de reglamentos, usos o prácticas que constituyan discriminación previsto en el artículo 2.f de la CEDAW. El Comité CEDAW, en la Recomendación General 28, también ha señalado que los Estados partes deben regular y sancionar las prácticas de discriminación interseccional teniendo en cuenta el impacto que producen en las mujeres afectadas (2010, párr. 18).

Por ello, dentro de las medidas para prevenir actos de discriminación se encuentra la obligación de combatir los estereotipos (Corte Interamericana de Derechos Humanos, 2012, párr. 302). Esto implica poner atención también a aquellas valoraciones que se tienen respecto de colectivos que enfrentan discriminación interseccional. En ese sentido, la promoción de imágenes positivas de las mujeres con discapacidad es necesaria para poder evitar que ellas sigan sufriendo la negación de sus derechos. En los siguientes acápites nos referiremos al contenido específico de esta obligación.

\subsection{El deber de erradicar estereotipos de género y de discapacidad}

La obligación de erradicar estereotipos basados en la idea de superioridad del hombre sobre la mujer está establecida de manera general en el artículo 5.a de la CEDAW, que dispone que los Estados deben tomar medidas con el siguiente fin:

“a) Modificar los patrones socioculturales de conducta de hombres y mujeres, con miras a alcanzar la eliminación de los prejuicios y las prácticas consuetudinarias y de cualquier otra índole que estén basados en la idea de la inferioridad o superioridad de cualquiera de los sexos o en funciones estereotipadas de hombres y mujeres;" 
El mandato de toma de conciencia en la Convención Internacional sobre los Derechos de las Personas con Discapacidad frente a los estereotipos interseccionales en medios de comunicación sobre mujeres con discapacidad

The awareness mandate of the Convention on the Rights of Persons with Disabilities as against intersectional stereotypes in the media on women with disabilities

De manera previa, la Convención Interamericana para prevenir, sancionar y erradicar la violencia contra la mujer, Convención de Belém Do Pará, había ido más allá del deber de "modificar, erradicar", y dispuso medidas preventivas en la lucha contra los estereotipos de género (Valega, 2019, pág. 42), al incluir:

“(...) el diseño de programas de educación formales y no formales apropiados a todo nivel del proceso educativo, para contrarrestar prejuicios y costumbres y todo otro tipo de prácticas que se basen en la premisa de la inferioridad o superioridad de cualquiera de los géneros o en los papeles estereotipados para el hombre y la mujer que legitimizan [sic] o exacerban la violencia contra la mujer."

A partir de estas obligaciones, los Estados se encuentran obligados a "modificar prácticas estereotipadas en virtud del género por el impacto negativo de las mismas en las mujeres como grupo social" (Valega, 2019, pág. 42).

La Corte Interamericana ha definido los estereotipos de género "como una preconcepción de atributos o características poseídas o papeles que son o deberían ser ejecutados por hombres y mujeres respectivamente" (2009, 401; 2014: 268). El surgimiento de estos está relacionado con el "eje de jerarquización social" que ha considerado lo "masculino" como superior a lo "femenino" (Ruiz Bravo, 2001, pág. 10). En esa línea, como señala Olsen, frente a los binomios "racional/irracional, activo/pasivo, pensamiento/sentimiento, razón/emoción, cultura/naturaleza, poder/sensibilidad, objetivo/subjetivo, abstracto/concreto, universal/particular", el pensamiento occidental ha sobrevalorado e identificado con lo masculino al primer elemento de estos binomios, es decir, lo racional, lo activo, el pensamiento, la razón, la cultura, el poder, lo objetivo, lo abstracto y lo universal (Olsen, 1990, pág. 452). Por otro lado, las mujeres han sido identificadas con el segundo elemento de estos binomios, que gozan de una valoración cultural menor: lo irracional, lo pasivo, el sentimiento, la emoción, la naturaleza, la sensibilidad, lo subjetivo, lo concreto, lo particular (Olsen, 1990, pág. 452).

Es importante precisar que los estereotipos pueden ser negativos (por ejemplo, asumir que las mujeres son "débiles") y aparentemente benignos (como suponer que las mujeres son "más sensibles") (Alto Comisionado de las Naciones Unidas para los Derechos Humanos, 2013, pág. 18). No obstante, estos últimos pueden usarse para construir discursos orientados a limitar o impedir los derechos de las mujeres, como aquel que presupone que son más sensibles, por lo que deben preferir ciertas profesiones sobre otras, como la psicología o la educación inicial. En ese sentido, la obligación de combatir estereotipos alcanza no solo a aquellos considerados negativos, sino también a los que, en un primer momento, pudieran pensarse que son benignos. Adicionalmente, cabe mencionar que el presente documento, más adelante, propondrá la noción de estereotipos neutrales, para ciertos discursos como los de prensa.
Los estereotipos de género permanecen en el tiempo (Corte Interamericana de Derechos Humanos, 2009, párr. 401), siendo replicados por la familia, la escuela, los medios de comunicación, entre otras instituciones, y promueven la subordinación de la mujer en la sociedad. La situación se agrava, además, cuando estos se ven reflejados en políticas y prácticas de autoridades estatales que vulneran los derechos de las mujeres en situaciones de violencia de género (Corte Interamericana de Derechos Humanos, 2009, párr. 401; 2015, párr. 180).

De manera específica, Cook y Cusack los han clasificado en cuatros grupos: (i) estereotipos de sexo, referidos a la preconcepción sobre los atributos físicos o biológicos de hombres y mujeres; (ii) estereotipos sexuales, aquellos que referidos a las características o cualidades sexuales de hombres y mujeres; (iii) estereotipos sobre los roles sexuales, los comportamientos esperados o apropiados para hombres y mujeres; y (iv) los estereotipos compuestos, referidos a aquellos que se construyen a partir de la interacción del género con otras estructuras de poder (2010, pág. 29-34). De acuerdo con Valega, estos estereotipos deberían ser denominados "estereotipos interseccionales" (2019, pág. 23). Precisamente, la discapacidad está entre las estructuras de poder señaladas como componente de los estereotipos compuestos.

En ese sentido, de manera complementaria, el artículo 8 de la CDPD establece el deber de evitar la perpetuación de estereotipos sobre las capacidades de las personas con discapacidad que se configuran como barreras para alcanzar sus derechos, y señala:

"Artículo 8. Toma de conciencia

1. Los Estados Partes se comprometen a adoptar medidas inmediatas, efectivas y pertinentes para:

a) Sensibilizar a la sociedad, incluso a nivel familiar, para que tome mayor conciencia respecto de las personas con discapacidad y fomentar el respeto de los derechos y la dignidad de estas personas;

b) Luchar contra los estereotipos, los prejuicios y las prácticas nocivas respecto 
de las personas con discapacidad, incluidos los que se basan en el género o la edad, en todos los ámbitos de la vida;

c) Promover la toma de conciencia respecto de las capacidades y aportaciones de las personas con discapacidad.

2. Las medidas a este fin incluyen:

a) Poner en marcha y mantener campañas efectivas de sensibilización pública destinadas a:

i) Fomentar actitudes receptivas respecto de los derechos de las personas con discapacidad;

ii) Promover percepciones positivas y una mayor conciencia social respecto de las personas con discapacidad;

iii) Promover el reconocimiento de las capacidades, los méritos y las habilidades de las personas con discapacidad y de sus aportaciones en relación con el lugar de trabajo y el mercado laboral;

b) Fomentar en todos los niveles del sistema educativo, incluso entre todos los niños y las niñas desde una edad temprana, una actitud de respeto de los derechos de las personas con discapacidad;

c) Alentar a todos los órganos de los medios de comunicación a que difundan una imagen de las personas con discapacidad que sea compatible con el propósito de la presente Convención;

d) Promover programas de formación sobre sensibilización que tengan en cuenta a las personas con discapacidad y los derechos de estas personas".

El contenido del artículo 8 no ha sido desarrollado por la jurisprudencia del Comité PCD. De igual manera, las Observaciones Finales de dicho órgano no han generado estándares claros sobre las obligaciones que tienen los Estados (Bariffi, 2018, pág. 242). No obstante, de manera general, se puede decir que el artículo 8 establece en su primer párrafo tres obligaciones para los Estados: (i) la sensibilización por los derechos, (ii) la lucha contra los estereotipos y (iii) la toma de conciencia sobre los aportes de las personas con discapacidad. Complementando ello, las Observaciones Finales del Comité PCD han especificado que los Estados deben generar campañas de toma de conciencia sobre los derechos de personas con discapacidad o que promuevan una imagen positiva, y que estas deben realizarse en consulta con organizaciones de personas con discapacidad (2016b, párr. 28; 2016c, párr. 15; 2015a, párr. 21; 2015b, párr. 16; 2015c, párr. 20; 2014a, párr. 18; 2014b, párr. 22; 2013, párr. 22).

Adicionalmente, y con miras en la interseccionalidad, para el caso de la Unión Europea, el Comité PCD solicitó que las campañas que combatiesen prejuicios tuviesen en cuenta a niñas y mujeres con discapacidad (2015d, párr. 27). Además, con respecto a los derechos de mujeres con discapacidad previsto en el artículo 6 de la CDPD, también indicó que se deben realizar campañas para realizar estereotipos en los casos de Qatar, China y Túnez (Comité PCD, 2015e, párr. 14; 2012b, párr. 58; 2011, párr. 15).

\subsection{El deber de erradicar estereotipos compuestos como medida de prevención de la discriminación interseccional}

El cumplimiento del artículo 5.a de la CEDAW y 8 de la CDPD de manera conjunta resulta necesario para la identificación de aquellas prácticas, valoraciones sociales y preconcepciones que se tienen de las mujeres con discapacidad y que contribuyen a promover situaciones de discriminación interseccional. Ello porque, como ya señalamos, el género se interseca con otros rasgos de la personalidad en formas muy variadas y da lugar a lo que Cook y Cusack han denominado "estereotipos compuestos" (2010, pág. 34-36) o "estereotipos interseccionales" (Valega, 2019, pág. 23). Estos reflejan preconcepciones falsas sobre diferentes subcategorías de mujeres y evolucionan de acuerdo con las diferentes articulaciones que existan sobre el patriarcado y las estructuras de poder (Fenton 1998, pág. 10-25, citado por Cook y Cusack 2010, pág. 34). Además, "impiden la eliminación de todas las formas de discriminación contra las mujeres y la materialización de la igualdad sustancial" (Cook y Cusack 2010, pág. 34). Estos se construyen sobre la base de categorías como la edad, el origen étnico, la discapacidad, la situación social o política, entre otros.

En el caso de las mujeres con discapacidad, es importante tener en cuenta que este grupo no resulta homogéneo. Por un lado, nos encontramos frente a mujeres de diferentes orígenes étnicos, religiosos y raciales, refugiadas, solicitantes de asilo, desplazadas internas, indígenas, privadas de libertad, en situación de pobreza, con discapacidades múltiples, con albinismo, y mujeres lesbianas, bisexuales, trans e intersexuales (Comité PCD 2016a, párr. 5). Por otro lado, dicha diversidad también incluye todos los tipos de deficiencias: físicas, intelectuales, mentales, psicosociales o sensoriales (Comité PCD 2016a, párr. 5).

De acuerdo con Serra, los estereotipos dañinos hacia las mujeres con discapacidad pueden clasificarse en falsos y proteccionistas 
El mandato de toma de conciencia en la Convención Internacional sobre los Derechos de las Personas con Discapacidad frente a los estereotipos interseccionales en medios de comunicación sobre mujeres con discapacidad

The awareness mandate of the Convention on the Rights of Persons with Disabilities as against intersectional stereotypes in the media on women with disabilities

(2016, pág. 302); reflejando los primeros una creencia falsa respecto de un grupo social, mientras que los estereotipos proteccionistas, de fundamento paternalista, asumen que las mujeres con discapacidad merecen una protección reforzada porque ellas no pueden decidir lo que es mejor para sus vidas. Sin embargo, en ambos casos es la condición de mujer la determinante para la formación de estos; en ese sentido, el cuerpo de la mujer será un factor clave en la construcción del estereotipo (Butler 2018, pág. 200). Lo paradójico, no obstante, es que las valoraciones sociales que se tienen de las mujeres con discapacidad serán inversas a las que suelen evidenciarse respecto de las mujeres sin discapacidad.

Así, mientras que a las mujeres se las suele asociar con la idea de que tienen que ser sensuales o provocativas, un estereotipo falso asignado a las mujeres con discapacidad es la creencia de que estas son asexuadas, que no son capaces de sentir placer en razón de su discapacidad y su condición de mujer (Minieri 2017, pág. 25). De igual manera, se puede mencionar la infantilización a la mujer con discapacidad, que también pone en tela de juicio su capacidad para tomar decisiones sobre su cuerpo y genera, además, prácticas de esterilización no consentidas bajo la justificación del mejor interés de ella(6) (Comité PCD 2016a, párr. 12 y 30; Serra 2016, pág. 302). Estos estereotipos han encontrado asidero en los medios de comunicación, como se ha evidenciado en diferentes estudios. Se señala, por ejemplo, que las mujeres con discapacidad han sido frecuentemente presentadas como asexuales o poco atractivas por causa de su discapacidad, justificando de esta manera la infidelidad de la que son víctimas (Barnes 1992, pág. 16-17).

En relación con los estereotipos proteccionistas podemos señalar que mientras que a la mujer se la asocia con la maternidad debido a la exacerbación de su rol reproductor en el que "la maternidad es el destino de toda mujer", en el caso de las mujeres con discapacidad, se les considera incapaces de ser madres (Serra 2016, pág. 405). Este estereotipo se justifica en el miedo de la sociedad a que: (i) la madre con discapacidad no cuente con suficientes recursos para cuidar a un/a bebé, (ii) la madre con discapacidad no pueda sobreponerse a los cambios físicos, o (iii) el/la bebé herede la discapacidad de su madre (Asamblea General del Foro Europeo de la Discapacidad 2011, párr. 8.7). Es por ello que se desalienta o impide que las mujeres con discapacidad ejerzan su maternidad.

Como se ve en los dos ejemplos, los estereotipos están fuertemente relacionados con el cuerpo de la mujer; en el caso de la mujer con discapacidad, de forma desalentadora (tanto del ejercicio de su sexualidad como de su capacidad reproductiva). En relación con la presencia de estos estereotipos proteccionistas en los medios, un estudio comparativo realizado en Canadá entre los años 1998 y 2008 mostró que habían marcadas diferencias en la presentación de una persona como sujeto de lástima, dependiendo de la variable de género: en el primer periodo de análisis, el uso de un lenguaje victimizante para referirse a la discapacidad de las mujeres era prevalente en el $70 \%$ de los casos frente a un $45 \%$ para los hombres (Devotta, Wilton \& Yiannakoulias, 2013, pág. 1864).

Por supuesto, estos no son los únicos estereotipos que pueden identificarse con respecto a las mujeres con discapacidad. En un estudio sobre prensa escrita en Perú se ha encontrado que la cobertura sobre los temas que las afectan es deficiente en términos de profundidad de la información y selección de fuentes especializadas, entre otros (Constantino, Ramos, Bregaglio \& Verano, 2018, pág. 68-73). También se podría afirmar que los medios han sido más propensos a revelar información sensible asociada con la discapacidad en el caso de las mujeres. Así, un estudio sobre medios suecos, se encontró que cuando se reportaban noticias sobre crímenes cometidos presuntamente por personas con discapacidad mental, los medios brindaban mayor información sobre la identidad de las mujeres con discapacidad mental que sus pares masculinos; y que era más frecuente encontrar información sobre mujeres famosas que daban testimonio sobre sus condiciones de salud mental (Ljuslinder, Morlandstø \& Mataityte-Dirziene, 2009, pág. 26). Por otro lado, el estereotipo también puede calar en detalles de la cobertura. Así, en una evaluación de medios estadounidenses se ha podido comprobar que es más frecuente solicitar a un hombre con discapacidad que sirva como fuente informativa para los periodistas. Ellos representaron más del doble del porcentaje que las mujeres (Haller, 1999, pág. 11).

La existencia de los estereotipos, su difusión y la falta de mecanismos para combatirlos generan un contexto propicio

(6) La Defensoría del Pueblo, en su Informe Defensorial №102 del 2005, constató que, en los establecimientos de internamiento, la aplicación de la anticoncepción quirúrgica voluntaria en mujeres con discapacidad mental dependía de la determinación de una junta médica y del consentimiento del familiar más cercano, mas no de la propia mujer con discapacidad. 
para la vulneración de los derechos de este colectivo. Tales violaciones pueden ser diversas, pero, principalmente, tendrán que ver sobre la posibilidad de tomar decisiones sobre sus vidas. Esto se verá agravado en los casos de derechos sexuales y reproductivos, debido a la existencia de leyes, políticas, programas y prácticas que restringen su ejercicio (Minieri, 2017, pág. 26).

De acuerdo con una investigación previa sobre prensa peruana, es posible identificar trece tipos diferentes de estereotipos referidos a mujeres con discapacidad. (Constantino, Ramos, Bregaglio \& Verano, 2018). Reconfigurando la clasificación propuesta por el Alto Comisionado de Naciones Unidas para los Derechos Humanos (Alto Comisionado de las Naciones Unidas para los Derechos Humanos 2013) y de Serra (Serra 2016, pág. 302), se propondrá la siguiente clasificación para los estereotipos: benignos, neutrales y dañinos. Los primeros se dividirán en adecuadamente benignos y aparentemente benignos. Los últimos, en falsos y proteccionistas.

Los estereotipos adecuadamente benignos serán aquellos que reflejan de manera adecuada las capacidades de las mujeres con discapacidad. En la investigación hemos encontrado que tres de los estereotipos calzan allí: (i) "las mujeres con discapacidad también pueden incluirse en actividades sociales (estudiar, trabajar, practicar deportes)", (ii) "las mujeres con discapacidad se pueden empoderar a través del activismo" y (iii) "las mujeres con discapacidad pueden ser destacadas en los ámbitos en que participen". Por otro lado, los estereotipos aparentemente benignos retratarán una visión positiva o neutral de algunas mujeres con discapacidad, aunque de una manera que refuerza ideas inadecuadas sobre ellas. Así, por ejemplo, se puede ubicar un estereotipo: "las mujeres con discapacidad pueden 'superarla' y tener una vida normal". Si bien muestra a las mujeres con discapacidad de manera positiva o neutral, pueden alimentar la narrativa de que ellas valen solamente si "superan" la discapacidad, sin incidir en la necesidad de modificar las barreras estructurales del entorno.

Los estereotipos neutrales tienen que ver con situaciones en las que las mujeres con discapacidad participan, aunque no como protagonistas sino principalmente como receptoras en hechos objetivos. Así, podemos contar dos estereotipos relacionados: (i) "las mujeres con discapacidad reciben apoyo de personalidades destacadas" y (ii) "la violencia de género puede producir una discapacidad". Ambos casos reflejan hechos, pero podrían incentivar visiones que describen a la discapacidad como un objeto de protección o una tragedia.

Por otro lado, entre los estereotipos dañinos proteccionistas se pueden contar los siguientes cinco: (i) "las mujeres con discapacidad son objeto de caridad", (ii) "las mujeres con discapacidad deben recibir intervención médica”, (iii) "las mujeres con discapacidad requieren de apoyo externo, no pueden cuidarse a sí mismas", (iv) "la discapacidad es una tragedia para las mujeres que la tienen" y (v) "las mujeres con discapacidad son vulnerables a la violencia". En todos estos casos la mujer con discapacidad aparece como un ser que requiere una protección, lo cual deja poco espacio para la agencia de ella misma, o que se justifica bajo la premisa de que la vida de una mujer con discapacidad es trágica o menos valiosa. Finalmente, como estereotipos dañinos falsos se contabilizan los siguientes dos: (i) "las mujeres con discapacidad pueden ser peligrosas" y (ii) "las mujeres con discapacidad no pueden ser buenas madres". En ambos casos, se puede ver como la interseccionalidad genera estereotipos particulares que buscan justificar, como se dijo líneas arriba, el impedimento del ejercicio de derechos sexuales y reproductivos. Vale la pena señalar que, si bien estos conceptos responden solo a la muestra analizada, se puede reconocer que los discursos sobre mujeres con discapacidad (manifestados también de manera actitudinal) reposan bastante en los estereotipos indicados.

\section{El rol de los medios en la no discriminación en la lucha contra los estereotipos}

Dado que la existencia, prevalencia y difusión de estos estereotipos excluye a las mujeres con discapacidad de una serie de derechos, es deber del Estado lograr cambiar las actitudes sociales que se permean en las diferentes instituciones y deniegan derechos. Para ello, evidentemente, el rol de los medios de comunicación resulta crucial, y ello será abordado en el presente acápite.

El artículo 8 de la CDPD, en su segundo párrafo, tiene el propósito de señalar los ámbitos sobre los cuales los Estados deben trabajar para combatir la prevalencia de estereotipos sobre personas con discapacidad. Son cuatro las medidas que dispone en específico: (i) la realización de campañas públicas con fines de sensibilización, (ii) el fomento del respeto a los estudiantes con discapacidad, (iii) la promoción de una imagen positiva de las personas con discapacidad en 
El mandato de toma de conciencia en la Convención Internacional sobre los Derechos de las Personas con Discapacidad frente a los estereotipos interseccionales en medios de comunicación sobre mujeres con discapacidad

The awareness mandate of the Convention on the Rights of Persons with Disabilities as against intersectional stereotypes in the media on women with disabilities

los medios de comunicación, y (iv) la realización de programas formativos para dar a conocer los derechos de las personas con discapacidad.

La primera y la cuarta medida podrían sonar conocidas para la sociedad civil, pues las acciones de formación y sensibilización tienen tiempo realizándose, y frecuentemente tienen objetivos a nivel micro (capacitación a funcionarios de un organismo, sensibilización en una o varias escuelas, entre otros). La segunda medida, sobre el respeto en ámbitos educativos, parece apuntar a una problemática específica y fundamental, que es el acceso a un espacio formativo y de socialización básica, en el cual cada persona puede aprender sobre el valor de la diversidad a través de la interacción con sus pares. Pero es el tercer punto, sobre la promoción de una imagen positiva de las personas con discapacidad en medios, el que podría brindar más posibilidades de acción en términos de políticas públicas, especialmente relacionadas a los medios de comunicación.

Sobre este deber de promover una imagen positiva, es pertinente precisar que en su versión en inglés ${ }^{(7)}$, la CDPD establece el deber de "fomentar (encouraging), desde los diferentes aparatos mediáticos (all organs of the media) una representación (to portray) de las personas con discapacidad" consistente con lo establecido por el mismo documento; mientras que la versión en español señala que se debe "alentar a todos los órganos de los medios de comunicación a que "difundan" una imagen de las personas con discapacidad que sea compatible con el propósito de la presente Convención"(8). En ese sentido, no establece de manera precisa cuáles son los medios en los que esta imagen positiva debe difundirse.

Si se adopta el texto de la norma en español, se observa que la norma se enfoca en los medios de comunicación de masas, es decir, aquellos que difunden, o, en otras palabras, diseminan contenidos simbólicos a públicos muy heterogéneos y amplios a través de elementos tecnológicos, aunque también cabría pensar que se pueden usar los medios de comunicación de masas para hacer llegar mensajes a públicos específicos (McQuail, 2000, pág. 40-41). Estos contenidos simbólicos son transmitidos y decodificados a través del lenguaje, que es en sí mismo un sistema de representaciones (Hall, 1997, pág. 4).
Realizar asociaciones desde el lenguaje con objetos y sujetos de la realidad que forman parte de nuestra experiencia en sociedad es una acción ineludible.

Ahora, asumir que el deber señalado por la norma recae sobre los medios de comunicación de masas implica comprender sus obligaciones desde una lógica unidireccional de información, que está presente en medios considerados "tradicionales" como la televisión, la radio, el cine o la prensa. En ellos, los mensajes que se emiten, con todas las cargas valorativas sobre las representaciones que ejecutan, se suelen asumir sin resistencia por parte de sus audiencias y de una forma que el emisor de dicho mensaje podría haber previsto (McQuail, 2000, pág. 567). Salvo situaciones excepcionales donde haya cierta interactividad $^{(9)}$ (como la conexión en vivo con personas que llamen telefónicamente), la interpretación del resto de contenidos en medios masivos queda únicamente en manos de una audiencia que, para comprender dichos contenidos, hace uso de su bagaje cultural, formado por experiencias de su propia vida cotidiana, los relatos de su entorno, y su exposición mediática.

En este contexto, el riesgo radica en aquellos mensajes que no encuentran resistencia en este proceso, pues se convierten en generalizaciones; esto es particularmente peligroso cuando se trata de representaciones de sujetos que, sea por socialización o por diferentes variables contextuales, no interactúan frecuentemente con nosotros. En este grupo se encuentran las personas con discapacidad que mayoritariamente viven en situaciones de exclusión social, entendida no solo como

(7) Como aparece en la web de la Organización de las Naciones Unidas, en el siguiente enlace: https://www.un.org/development/desa/ disabilities/convention-on-the-rights-of-persons-with-disabilities/article-8-awareness-raising.html. Consulta: 28 de agosto de 2019.

(8) Se puede consultar la versión en español en el siguiente enlace: https://www.minjus.gob.pe/wp-content/uploads/2014/03/CONVENCIONSOBRE-DERECHOS-PERSONAS-DISCAPACIDAD.pdf, página 7. Consulta: 28 de agosto de 2019. Las cursivas son nuestras.

(9) En la actualidad, y a nivel local, los medios masivos de comunicación siguen manteniendo un enfoque tradicional e unidireccional de flujo informativo en sus contenidos. El enfoque transmedia es aún incipiente en el país, y a veces se trabaja de manera superficial. Esto se observa cuando, por ejemplo, un periódico comparte exactamente el mismo texto e imágenes en su versión digital y en la impresa: a pesar de que la plataforma podría permitir una mayor interactividad del público, no se aprovecha esta herramienta en toda su potencialidad. Otro caso es el de los "tweets del público" que se muestran en algunas transmisiones, como las de deportes o noticias: se muestran los mensajes a los televidentes, pero no hay una conversación entre emisor y audiencia. En ese sentido, sí consideramos que los medios, a nivel general, no abren el diálogo a otros actores que no sean parte de la transmisión, y por ende reducen las posibilidades de observar un diálogo plural. 
de restricción de derechos, sino de absoluta invisibilización y ausencia en los espacios sociales como las calles, las escuelas o los centros de labores ${ }^{(10)}$. Cuando la única visión de la discapacidad que se tiene un grupo viene de los medios, y esta imagen no se trabaja con estándares de reconocimiento a la diversidad y de respeto a la dignidad humana, se configuran estereotipos que perjudican la interacción social de la persona con discapacidad (Guscinskiene \& Zalkauskaite, 2011, pág. 28), y es contra esto que se plantean las medidas relacionadas al proceso de toma de conciencia. En ese sentido, a partir del mandato del artículo 8 se debe lograr que el discurso de los medios respete el derecho al honor y a la buena reputación, a la intimidad personal y familiar, así como a la voz e imagen propia de las personas.

Por otro lado, debe resaltarse que el artículo 8 no ha planteado cómo debería posicionarse un Estado frente a discursos que promueven estereotipos y si se podría llegar a sancionar ciertos tipos de discurso. Al respecto, el Comité para la Eliminación de la Discriminación Racial (Comité CERD) ha señalado que la "libertad de expresión no debe tener por objeto la destrucción de los derechos y las libertades de otras personas, incluidos el derecho a la igualdad y a la no discriminación." (Comité CERD, 2013, párr. 23). Al mismo tiempo, ha recomendado a los Estados tomar medidas para tener leyes de comunicación masiva que se enmarquen en una cultura de derechos humanos y fomentar que los medios de comunicación tengan códigos deontológicos que incorporen respeto por los principios de los derechos humanos (Comité CERD, 2013, párr. 39). Esto sin duda resultaría trasladable a las obligaciones que plantea la CDPD. En el mismo sentido, en 2012, el Comité PCD hizo un Ilamado de atención por las continuas iniciativas privadas de recaudación de fondos que utilizan estereotipos negativos y planteamientos de beneficencia, como ocurre con la Teletón, formato que no solo se utiliza en Perú, sino en varios países del mundo (International Disability Alliance, 2017, pág. 49-50).

Al respecto, es necesario señalar que la regulación de los medios de comunicación masivos en el Perú es difusa. Si nos referimos a legislación específica, la Ley de Radio y Televisión ${ }^{(11)}$ establece que los medios deben autorregularse a través del cumplimiento del Código de Ética de la Sociedad Nacional de Radio y Televisión ${ }^{(12)}$ y el propio código de ética de cada medio $^{(13)}$. Sin embargo, los que no son de radiodifusión (como los impresos o los que se distribuyen vía web) no tienen una legislación equivalente. En casos referidos a racismo, si bien ha habido alguna sentencia que ha ordenado la suspensión de un programa que promovía estereotipos racistas, la misma no fue confirmada en segunda instancia ${ }^{(14)}$.

Además, el artículo 8 carece de un enfoque sobre los medios y la comunicación que considere la problemática que plantea la lógica multidireccional de plataformas de medios sociales en internet. El auge de estos medios se dio de manera casi simultánea a la entrada en vigor de la CDPD, por lo que esta carencia no podría pensarse como deliberada, pero en la actualidad no es posible seguir pasando por alto la forma en que funcionan estos soportes de comunicación. En ellos, la multiplicidad de emisores dificulta la tarea de verificar cómo se están haciendo las representaciones que podrían terminar siendo nocivas; también se debe considerar que los medios sociales, al presentarse como espacios de discusión, brindan una oportunidad para plantear nuevas formas de participación que terminen dando resultados positivos.

En esta línea, es conveniente apuntar brevemente cómo funcionan los procesos de representación en tres tipos bastante populares de mensaje mediático: (i) las noticias, (ii) los relatos de ficción seriada y (iii) la publicidad. Debe tenerse presente que, aunque las noticias y el contenido periodístico se caracterizan por tener la intención de realizar representaciones de manera fiel a la realidad, pues es parte de su razón de ser,

(10) A través de información demográfica presentada en la Primera Encuesta Nacional Especializada sobre Discapacidad, en el Perú esta realidad se plasma en índices más bajos de nivel educativo, porcentajes de éxito al momento de buscar empleos, y la afirmación de que aproximadamente el $40 \%$ es dependiente de otros para desarrollar sus actividades diarias (INEI 2014).

(11) Ley 28278, publicada en el Diario Oficial El Peruano el 16 de julio de 2004.

(12) Disponible en: http://snrtv.org.pe/codigo-de-etica/

(13) El Tribunal de Ética de la SNRTV ya cuenta con un antecedente a favor de la no discriminación hacia las mujeres con discapacidad (Resolución 003-2016 del Tribunal de Ética de la Sociedad Nacional de Radio y Televisión). A su vez, ciertos organismos públicos ya están habilitando la posibilidad de pensar en la lucha contra la discriminación a través de estereotipos como parte de sus políticas, como es el caso del referido Plan Nacional Contra la Violencia de Género 2016-2021. http://snrtv.org.pe/resolucion-003-2016cesnrtv-apelada-y-resuelta-por-el-tribunal-de-etica/. Consultado el 11 de octubre de 2019.

(14) Sala Civil del Cusco. Sentencia de 22 de mayo del 2019 recaída en el expediente 00798-2014-0-1001-JM-Cl-01. Disponible en: https://static.legis.pe/wp-content/uploads/2019/06/Exp.-00798-2014-1001-JM-Cl-01-Legis.pe_. pdf?fbclid=IwAR28WEt4xBSB1K1eRIffiqY1qvRt7363PABe3oVybyH0bHzmitay0YVegnw 
El mandato de toma de conciencia en la Convención Internacional sobre los Derechos de las Personas con Discapacidad frente a los estereotipos interseccionales en medios de comunicación sobre mujeres con discapacidad

The awareness mandate of the Convention on the Rights of Persons with Disabilities as against intersectional stereotypes in the media on women with disabilities

al menos de modo vocacional (Rodrigo, 2005, pág. 51-52), lo finalmente proyectado es aquello que: (i) ha pasado por un filtro de relevancia social desarrollado por los editores y los propios reporteros, que son conscientes de que no todo lo acontecido puede terminar siendo informado masivamente; y (ii) está sesgado por la información que tiene el/la periodista sobre el tema que desarrolla e incluso por su propia subjetividad. Por ello, diversos autores han afirmado que la objetividad periodística es solo un ideal, pero que ha servido para al menos tener una idea de qué quiere lograr el periodismo, y que termina siendo lo que lo distingue de otras formas de comunicación: el compromiso con la verdad (Kovach \& Rosenstiel, 2007, pág. 41).

En este contexto, un periodismo responsable con las mujeres con discapacidad debería adaptar una mirada inclusiva en más de un ámbito. En primer lugar, debe buscar balancear su mirada sobre estas personas de tal forma que refleje sus demandas por accesibilidad, que son un asunto público y evidencia de lo que este colectivo aún no puede lograr por culpa de las barreras sociales. En segundo lugar, debe destacar las consecuencias positivas de contar con un entorno inclusivo y que permiten a varias de estas personas lograr cosas extraordinarias incluso para la población sin discapacidad, aunque hablar de lo extraordinario en cosas que deberían ser cotidianos debe hacerse con cuidado para no caer en el vicio de presentar como heroico y desprendido lo que por dignidad y por ley les corresponde a las personas con discapacidad. Por otro lado, también debe considerar que una visión inclusiva del mundo solo sería coherente con una política de inclusión dentro del mismo equipo periodístico, y debe procurar darle cabida a profesionales que tengan discapacidad, brindándoles los ajustes razonables necesarios.

Si hablamos de contenidos de ficción, sean series, novelas, películas o videos musicales (entre otros), a través de varios estudios (Barnes, 1992; Stuart, 2006) se ha evidenciado un encasillamiento de ciertos roles de personas con discapacidad en estereotipos que perjudican su valoración y los hacen ver como seres peligrosos o dignos de lástima. ${ }^{(15)}$ Asimismo, se les ha considerado por mucho tiempo como un elemento cuya función es la de presentarse como una prueba u obstáculo para otro personaje, convirtiéndose su representación en un acto completamente instrumental(16). Por ello, los guionistas deben esforzarse en hacer una investigación adecuada para desarrollar personajes con discapacidad que reflejen apropiadamente lo que estas personas realmente pueden sentir, pensar o enfrentar en su vida diaria, sin importar las características del universo ficcional en el cual estén inscritas. Además, los responsables de casting deben brindar la oportunidad de participar a actores y actrices con discapacidad para roles en los que el personaje también tiene una (con lo que contribuyen a realizar una representación más adecuada). Incluso, se debería considerar la posibilidad de incluirlos como opciones para roles que se han pensado sin discapacidad, y en caso la trama se vea afectada por esta circunstancia, pensar en la posibilidad de adaptarla.

En tercer lugar, para pensar en contenidos publicitarios se debe tener en cuenta que su misión comunicativa es la suscitar necesidades, por lo que toda representación que se hace es parte de un sistema de connotaciones cuyo fin último es presentar como deseable un objeto o servicio (Moles \& Costa, 1999, pág. 43). Esta forma de mensaje puede trabajar desde un universo completamente ficcional, pero también hacer uso de personajes que en la vida real son reconocibles y actúan de "sí mismos" y prestan su imagen para promocionar el consumo de algún bien. Con esto en consideración, se puede pensar de dos formas de inclusión: la presentación de más personas con discapacidad como role models y embajadores de marcas cuyos valores se adhieran a la imagen por la que estas personas destacan (como es el caso de los atletas que auspician marcas deportivas o alimentos saludables); y también debe considerarse la contratación de actores y actrices con discapacidad para aparecer como usuarios de los productos que se promocionan. Esto ocurre cada vez con más frecuencia en el rubro infantil, que en nuestro país ha empezado a incorporar niños y niñas con Síndrome de Down en la publicidad de ropa, juguetes o servicios ${ }^{(17)}$.

(15) Así, una representación común de los villanos es que tengan alguna discapacidad. Por ejemplo, Ricardo III es representado como cojo y jorobado; el Doctor No, villano de la saga de Bond, no tiene manos, al igual que el Capitán Garfio de Peter Pan.

(16) Al respecto, durante mucho tiempo, los personajes con discapacidad en realidad permiten que el protagonista sin discapacidad pueda entrar en un proceso de mejora personal. Son ejemplos contemporáneos la película Rainman o Buscando a Nemo.

(17) Últimamente se ha podido observar que algunos catálogos publicitarios están incluyendo niños y niñas con discapacidad como modelos. La asociación Colectivo 21 ha llamado la atención de dos de ellas: una de la marca Roots de ropa para niños y bebés (https://www.facebook.com/Colectivo21Peru/posts/646039439246716) y otra de la cadena de supermercados Plaza Vea (https:// www.facebook.com/Colectivo21Peru/posts/643036382880355) 
Finalmente, debe pensarse en las personas con discapacidad como un sector de la audiencia que debe ser atendido. En este caso, no nos estamos refiriendo a la accesibilidad (establecida por el artículo 21), pues se trata de un criterio técnico, sino de la lógica mediática de considerar a un grupo como un potencial consumidor y crear contenidos que atiendan sus demandas. Si la CDPD no asume esta demanda, la única alternativa que queda es que el colectivo de personas con discapacidad tome acciones para solicitar mayor atención a los medios, cuyas decisiones editoriales suelen partir de una lógica mercantilista antes que de una obligación frente a los derechos de las personas.

\section{Conclusiones}

La CDPD reconoce que la inclusión no depende únicamente del Estado, sino que es un esfuerzo social integral (Mégret, 2008, pág. 266-268). Por tanto, se hace necesario que los esfuerzos que apuntan a la modificación del contexto social que genera la discapacidad sean abordados de manera conjunta por la sociedad y el Estado.

Entre los factores que crean y perpetúan la discriminación se encuentran los estereotipos sobre las mujeres con discapacidad. Lo que se piensa de ellas afecta sus posibilidades para acceder y ejercer derechos en igualdad de condiciones con los demás, razón por la cual el Estado tiene que tomar medidas que activamente desmonten los imaginarios sociales que posibilitan la discriminación.

Los medios de comunicación, de toda índole, deben incluir visiones respetuosas de las mujeres con discapacidad que no las retraten perpetuando estereotipos, sino mostrando la complejidad de su contexto, tal como se hace con el resto. Para ello, toca aplicar los artículos 5 CEDAW y 8 CDPD de manera combinada, y lograr que existan iniciativas, planes y estrategias públicas que desmonten estereotipos, y medios (públicos y privados) que adopten políticas claras para renunciar a visiones prejuiciosas sobre este colectivo.

\section{Referencias bibliográficas}

Alto Comisionado de las Naciones Unidas para los Derechos Humanos (2012). Estudio temático sobre la cuestión de la violencia contra las mujeres y las niñas y la discapacidad. A/HRC/20/5. 30 de marzo de 2012. Recuperado de: https://undocs.org/A/HRC/20/5

Alto Comisionado de las Naciones Unidas para los Derechos Humanos (2013). Gender Stereotyping as a Human Rights Violation. Recuperado de http://www.ohchr.org/Documents/Issues/Women/WRGS/2013Gender-Stereotyping-as-HRViolation.docx

Asamblea General del Foro Europeo de la Discapacidad (2011). Segundo Manifiesto de los Derechos de las Mujeres y Niñas con Discapacidad de la Unión Europea. Una herramienta para activistas y responsables políticos. Adoptado en Budapest los días 28 y 29 de Mayo de 2011 por la Asamblea General del Foro Europeo de la Discapacidad, a propuesta de su Comité de Mujeres. Recuperado de: https://www.cermi.es/sites/default/files/docs/ informes/2\%C2\%BA\%20Manifiesto\%20de\%20 los $\% 20$ Derechos $\% 20$ de $\% 20$ las $\% 20$ Mujeres $\% 20$ y\%20Ninas $\% 20$ con $\% 20$ Discapacidad $\% 20$ de $\% 20$ La\%20Union\%20Europea\%20accesible.pdf

Aylward, Carol (2010). Intersectionality: Crossing the Theoretical and Praxis Divide. Journal of Critical Race Inquiry, 1(1), 1-48. https://doi.org/10.24908/ jcri.v1i1.3549

Bariffi, Francisco (2018). Article 8. Awareness Raising. En: Batenkas, Ilias; Stein, Michael Ashley \& Anastasiou, Dēmētrē (Eds.). The UN Convention on the Rights of Persons with Disabilities, a commentary. Oxford commentaries on international law. Oxford: Oxford University Press.

Barnes, Colin. (1992). Disabling imagery and the media. An exploration of the principles for media representations of disabled people. Halifax: The British Council of Organisations of Disabled People and Ryburn Publishing Limited. Recuperado de: https://disability-studies.leeds.ac.uk/wp-content/ uploads/sites/40/library/Barnes-disabling-imagery. pdf

Barnes, Colin \& Oliver, Michael. (2012). The New Politics of Disablement. Londres: Palgrave.

Barton, Len. (2009). La posición de las personas con discapacidad ¿Qué celebrar y por qué celebrarlo? ¿Cuáles son las consecuencias para los participantes? En: Brogna, Patricia (Comp.), Visiones y Revisiones de la Discapacidad, 23-137. Ciudad de México: Fondo de Cultura Económica.

Bernárdez, Asunción. (2015). Mujeres en medio(s). Propuestas para analizar la comunicación masiva con perspectiva de género. Madrid: Editorial Fundamentos.

Butler, Judith. (2018). El género en disputa. El feminismo y la subversión de la identidad. Lima: Planeta (Original publicado en 1990).

Charlesworth, Hilary \& Chinkin, Christine. (2017). El género del ius cogens. Revista Latinoamericana de Derecho Internacional, 7. Recuperado de: http:// revistaladi.com.ar/wp-content/uploads/2018/06/ LADI-n7-Chinkin-y-Charlesworth-El-género-deljus-cogens.pdf

Comité para la Eliminación de la Discriminación contra la Mujer. (2010). Recomendación General Nro. 28 relativa a las obligaciones básicas de los Estados partes de conformidad con el artículo 2 de la Convención sobre la Eliminación de Todas las Formas de Discriminación contra la Mujer. CEDAW/C/GC/28. 16 de diciembre de 2010. Recuperado de: https://tbinternet.ohchr.org/_ 
El mandato de toma de conciencia en la Convención Internacional sobre los Derechos de las Personas con Discapacidad frente a los estereotipos interseccionales en medios de comunicación sobre mujeres con discapacidad

The awareness mandate of the Convention on the Rights of Persons with Disabilities as against intersectional stereotypes in the media on women with disabilities

layouts/15/treatybodyexternal/Download.aspx?symbolno=CEDAW/C/ $\mathrm{GC} / 28 \&$ Lang=en

(2014). Comunicación $N^{\circ} 34 / 2011$. Dictamen aprobado por el Comité en su $57^{\circ}$ período de sesiones, 10 a 28 de febrero de 2014. CEDAW/C/57/D/34/2011. 12 de marzo de 2014. Recuperado de: https://bit.ly/2nTpZiB

(2017). Recomendación general $N^{\circ} 35$ sobre la violencia por razón de género contra la mujer, por la que se actualiza la recomendación general $N^{\circ} 19$. CEDAW/C/GC/35. 26 de julio de 2017. Recuperado de: https://undocs.org/CEDAW/C/GC/35

Comité para la Eliminación de la Discriminación Racial. (2013). Recomendación general $N^{\circ} 35$. La lucha contra el discurso de odio racista. CERD/C/GC/35. 26 de septiembre de 2013 Recuperado de: http://docstore.ohchr.org/SelfServices/FilesHandler. ashx? enc $=6$ QkG1d\%2FPPRiCAqhKb7yhssy N NtgI51 ma 08 CMa6o7Bglz8iG4SuOjovEP\%2Bcqr8joDQWqe7tgHamAOAP SeR0m5B5 r8ckl6\%2FjbRZXQNUe1VCmrDgLSQf5ShN8J6ctjCfiiX

Comité sobre los Derechos de las Personas con Discapacidad (2011). Examen de los informes presentados por los Estados partes con arreglo al artículo 35 de la Convención. Observaciones finales del Comité sobre los Derechos de las Personas con Discapacidad. CRPD/C/TUN/ CO/1. 13 de mayo de 2011. Recuperado de: http://docstore.ohchr.org/ SelfServices/FilesHandler.ashx?enc $=6$ QkG1d\%2fPPRiCAqhKb7yhsv OO0RvDbzSfy057\%2fIfh1RwM0BYu1Nnxrjjo6vZmLus\%2b\%2f1 ZDuFiYNWHtW\%2fDL5M9e5E7YpYYuaLCCHD5CyQrUyfzFDHTW Co\%2bYbkrJ1woCKv15

(2012a). Observaciones finales del Comité sobre los Derechos de las Personas con Discapacidad. CRPD/C/PER/CO/1. 16 de mayo de 2012. Recuperado de: https://tbinternet.ohchr.org/ layouts/15/treatybodyexternal/Download.aspx?symbolno=CRPD/C/ $\mathrm{PER} / \mathrm{CO} / 1 \&$ Lang $=\mathrm{En}$

(2012b). Observaciones finales sobre el informe inicial de China, aprobadas por el Comité en su octavo período de sesiones (17 a 28 de septiembre de 2012). CRPD/C/CHN/CO/1. 15 de octubre de 2012. Recuperado de: http://docstore.ohchr.org/SelfServices/FilesHandler. ashx? enc $=6$ QkG1d\%2fPPRiCAqhKb7yhsrBkvDLHrFFq8wSO e2z9g3jLWXscOK3cW\%2bh6NEqWxDjRLAKgX49CP9xOmOSOnj0f JF7IIXxIT7jbjH0M311hQx6sZ\%2b9jIBH\%2fIVc\%2bb4T08MOZ

(2013). Observaciones finales sobre el informe inicial de Austria, aprobadas por el Comité en su décimo período de sesiones (2 a 13 de septiembre de 2013). CRPD/C/AUT/CO/1. 30 de septiembre de 2013. Recuperado de: http://docstore.ohchr.org/ SelfServices/FilesHandler.ashx?enc=6QkG1d\%2fPPRiCAqhKb7yhsnz SGolKOaUX8 SsM2PfxU7s9IOchc\%2bi0vJdc3TEt6JuQH6d6Lwu OqunaiCbf0Z0e\%2b3YP Od\%2b51urKZtNiegNn9fHI2wxVGr\%2f3ZV6 aDDoXITQ8

(2014a). Observaciones finales sobre el informe inicial de Bélgica. CRPD/C/BEL/CO/1. 28 de octubre de 2014. Recuperado de: https://undocs.org/es/CRPD/C/BEL/CO/1

(2014b). Observaciones finales sobre el informe inicial de Suecia. CRPD/C/SWE/CO/1. 12 de mayo de 2014. Recuperado de: https://tbinternet.ohchr.org/_layouts/15/treatybodyexternal/Download. aspx?symbolno=CRPD/C/SWE/CO/1\&Lang=En

(2015a). Observaciones finales sobre el informe inicial del Gabón. CRPD/C/GAB/CO/1. 2 de octubre de 2015. Recuperado de: https:// tbinternet.ohchr.org/_layouts/15/treatybodyexternal/ Download.aspx? symbolno= CRPD $\% 2 \mathrm{fC} \%$ 2fGAB\%2fCO $\% 2 f 1 \&$ Lang=en

(2015b). Observaciones finales sobre el informe inicial de Kenia. CRPD/C/ $\mathrm{KEN} / \mathrm{CO} / 1.30$ de septiembre de 2015. Recuperado de: https://tbinternet.ohchr.org/ layouts/15/treatybodyexternal/Download. aspx? symbolno=CRPD $\% 2 \mathrm{fC} \% 2 \mathrm{fKEN} \% 2 \mathrm{fCO}$ $\% 2 f 1 \&$ Lang $=$ en

(2015c). Observaciones finales sobre el informe inicial de Alemania. CRPD/C/DEU/CO/1. 13 de mayo de 2015. Recuperado de: https://tbinternet.ohchr.org/ layouts/15/treatybodyexternal/Download. aspx? symbolno=CRPD $\% 2 \mathrm{fC} \% 2 \mathrm{fDEU} \% 2 \mathrm{fCO}$ $\% 2 f 1 \&$ Lang $=$ en

(2015d). Observaciones finales sobre el informe inicial de la Unión Europea. CRPD/C/EU/CO/1. 2 de octubre de 2015 Recuperado de: https://tbinternet.ohchr.org/ layouts/15/treatybodyexternal/Download. aspx?symbolno=CRPD $\% 2 \mathrm{fC} \% 2 \mathrm{fEU} \% 2 \mathrm{fCO} \%$ 2f1\&Lang=en

(2015e). Observaciones finales sobre el informe inicial de Qatar. CRPD/C/QAT/CO/1. 2 de octubre de 2015. Recuperado de: https://daccessods.un.org/TMP/6778742.07496643.html

(2016a). Observación General Nro. 3, sobre las mujeres y niñas con discapacidad. Naciones Unidas: Convención sobre los derechos de las personas con discapacidad. CRPD/C/GC/3. 25 de noviembre de 2016. Recuperado de: https:// bit.ly/2SNFjr1

(2016b). Observaciones finales sobre el reporte inicial de Eslovaquia. CRPD/C/SVK/ CO/1. 17 de mayo de 2016. Recuperado de: http:// docstore.ohchr.org/SelfServices/FilesHandler. ash $x$ ?enc $=6$ QkG1d\%2fPPRiCAqhKb7yhsiV\%2bq 2wB82cxwrVotBOWJsruvUpS5Q9q\%2f\%2b4PqUC 1g032rG1 f\%2b\%2bWGWZJDq6htoJ\%2bb YAqiVre 7GR2VVx\%2fc14x6Nu5HkFhf3Fyawe8k MOaflQXu

(2016c). Observaciones finales sobre el informe inicial de Uganda. CRDP/C/UGA/CO/1. 12 de mayo de 2016. Recuperado de: https://tbinternet.ohchr.org/_ layouts/15/treatybodyexternal/Download. aspx?symbolno=CRPD $\% 2 \mathrm{fC} \% 2 \mathrm{fUGA} \% 2 \mathrm{fCO} \%$ 2f1\&Lang=en

(2018). Observación general núm. 6 (2018) sobre la igualdad y la no discriminación. CRPD/C/GC/6. 26 de abril de 2018. Recuperado de: https://tbinternet.ohchr. org/_layouts/15/treatybodyexternal/Download. aspx?symbolno=CRPD/C/GC/6\&Lang=en 
Constantino Caycho, Renato; Ramos Obregón, Valquiria; Bregaglio Lazarte, Renata; Verano, Cristina. (2018). Voces en off: La representación mediática de las mujeres con discapacidad en medios periodísticos impresos de Lima y Huancayo. Lima: FCEPD y COCEMFE. Recuperado de: https://issuu.com/generodiscapacidad/ docs/voces_en_off_-_diagramaci_n_final_a

Convención Interamericana para prevenir, sancionar y erradicar la violencia contra la Mujer "Convención de Belém do Pará". Entrada en vigor de 03 de mayo de 1995.

Convención sobre los Derechos de las Personas con Discapacidad. Entrada en vigor del 03 de mayo del 2008. U.N.T.S 2515, p. 3.

Cook, Rebecca \& Cusack, Simon. (2010). Estereotipos de género: Perspectivas legales transnacionales. Bogota: University of Pennsylvania Press. Recuperado de https://www.law.utoronto.ca/ utfl_file/count/documents/reprohealth/estereotipos-de-genero.pdf

Coomaraswamy, Radhika. (2001). Review of reports, studies and other documentation for the Preparatory Committee and the World Conference. A/CONF.189/PC.3/5

Corte Interamericana de Derechos Humanos. (2006). Caso del Penal Miguel Castro Castro Vs. Perú. Fondo, Reparaciones y Costas. Sentencia de 25 de noviembre de 2006. Serie C No. 160.

(2009). Caso Gonzáles y otras (“Campo Algodonero") vs. México. Excepción Preliminar, Fondo, Reparaciones y Costas. Sentencia de 16 de noviembre. Serie C No. 205.

(2012). Caso Artavia Murillo y otros (Fecundación in Vitro) vs. Costa Rica. Excepciones Preliminares, Fondo, Reparaciones y Costas. Sentencia de 28 de noviembre. Serie C No. 257.

(2014). Caso Espinoza Gonázales vs. Perú. Excepciones Preliminares, Fondo, Reparaciones y Costas. Sentencia de 20 de noviembre. Serie C No. 289.

(2015). Caso Velásquez Paiz y otros vs. Guatemala. Excepciones Preliminares, Fondo, Reparaciones y Costas. Sentencia de 19 de noviembre. Serie C No. 307.

(2019). Caso Mujeres Víctimas de Tortura Sexual en Atenco Vs. México. Excepción Preliminar, Fondo, Reparaciones y Costas. Sentencia de 28 de noviembre de 2018. Serie C No. 371.

Crenshaw, Kimberlé. (1991). Mapping the Margins: Intersectionality, Identity Politics and violence Against Women of Color. Stanford Law Review, 43(6), 1241-1299. Recuperado de: https://www.jstor.org/ stable/1229039

Cruz, María. (2013). Teoría feminista y discapacidad: un complicado encuentro en torno al cuerpo. Revista de Investigación y Divulgación sobre los Estudios de Género, 19(12), 51-71. Recuperado de: http:// revistasacademicas.ucol.mx/index.php/generos/article/view/634

Cuenca, Patricia. (2012). Los derechos fundamentales de las personas con discapacidad. Un análisis a la luz de la Convención de la ONU. Cuadernos de Democracia y Derechos Humanos. Número 7. Madrid: Universidad de Alcalá.

Devotta, Kimberly; Wilton, Robert \& Yiannakoulias, Niko. (2013). Representations of disability in the Canadian news media: A decade of change? Disability \& Rehabilitation, 35(22), 1859-1868. Recuperado de: https://www.ncbi.nlm.nih.gov/pubmed/23350765
Domínguez, María Eugenia, et. al. (2011). Derechos sexuales y reproductivos de las mujeres con discapacidad: estudio sobre la accesibilidad de los servicios de salud en Montevideo. Montevideo: Intendencia de Montevideo.

Fenton, Zanita. (1998) Domestic Violence in Black and White: Racialized Gender Stereotypes in Gender Violence. En: Columbia Journal of Gender \& Law, 8.

Gamarnik, Cora Edith. (s/f). Estereotipos sociales y medios de comunicación: un círculo vicioso. Buenos Aires: UNLP. Recuperado de: http://sedici.unlp.edu. ar/bitstream/handle/10915/33079/Documento_ completo.pdf?sequence $=1$ \&isAllowed $=y$

Guscinskiene, Jurate, \& Zalkauskaite, Ugne. (2011). Reflections of Disability in Lithuanian Media: The Case of Daily Newspaper the 'Lietuvos rytas". Socialiniai tyrimai / Social Research. 2(23), 24-36. Recuperado de: http://www.su.It/ bylos/mokslo_leidiniai/soc_tyrimai/2011_23/ guscinskiene_zalkauskaite.pdf

Hall, Stuart. (1997). Representation: Cultural Representations and Signifying Practices. Londres: Sage.

Haller, Beth. (1999). News coverage of disability issues: Final report for The Center for an Accessible Society. Center for an Accessible Society. Recuperado de: http://www.accessiblesociety.org/ topics/coverage/0799reportoverview.htm

International Disabilitiy Alliance. (2017). Informe de IDA sobre la primera misión de seguimiento a las recomendaciones del Comité de la CDPD a Perú. Australian Government, Ulkoasiainministeriö, Swedish International Development Cooperation Agency, Open Society Foundations. Recuperado de: http://www.internationaldisabilityalliance.org/ es/ida-informe-primera-2015

Jiménez F., Rosario \& Aguado, María Teresa. (2002). Pedagogía de la diversidad. Madrid: UNED.

Kovach, Bill \& Rosenstiel, Tom. (2007). The elements of journalism: what newspeople should know and the public should expect. Nueva York: Three Rivers Press.

Ley 28278, Ley de Radio y Televisión. Publicada en el Diario Oficial El Peruano el 16 de julio de 2004.

Ljuslinder, Karin; Morlandstø, Lisbeth \& MataityteDirziene, Jurga. (2009). Images of disabled in Lithuania-view from the Scandinavian perspective. Umea: Umea University. Recuperado de http://umu. diva-portal.org/smash/record.jsf?pid=diva2:271749

Mancini, Iván. (2014). En el bosque creativo de la publicidad. Lima: Universidad San Martín de Porres. 
El mandato de toma de conciencia en la Convención Internacional sobre los Derechos de las Personas con Discapacidad frente a los estereotipos interseccionales en medios de comunicación sobre mujeres con discapacidad

The awareness mandate of the Convention on the Rights of Persons with Disabilities as against intersectional stereotypes in the media on women with disabilities

McQuail, Denis. (2000). Introducción a la teoría de la comunicación de masas. 3ra ed. Barcelona: Paidós.

Mégret Frédéric (2008). The Disabilities Convention: Towards a Holistic Concept of Rights. The International Journal of Human Rights, 12(2).

Minieri, Sofia. (2017). Derechos sexuales y derechos reproductivos de las mujeres con discapacidad. Aportes teóricos para una agenda de incidencia inclusiva. Buenos Aires: Red por los Derechos de las Personas con Discapacidad (REDI).

Ministerio de la Mujer y Poblaciones Vulnerables. (2016). Violencia basada en género. Marco conceptual para las políticas públicas y la acción del Estado. Lima: Autor. Recuperado de: https:// www.mimp.gob.pe/files/direcciones/dgcvg/mimpmarco-conceptual-violencia-basada-en-genero.pdf

(2019). Estadísticas del Programa Nacional Contra la Violencia Familiar y Sexual MIMP. [Estadísticas en página web]. Recuperado de: https://observatorioviolencia.pe/datos-2/ datospncvfs/\#34_Casos_de_victimas_con_ discapacidad_atendidas_en_los_CEM_segun_ tipo_de_violencia_y_sexo_por_regiones

Mogollón, María Esther. (2004). Cuerpos diferentes: sexualidad y reproducción en mujeres con discapacidad. En: Cáceres, Carlos; Frasca, Timothy, Pecheny, Mario; Terto Júnior, Veriano (Eds.), Ciudadanía sexual en América Latina: abriendo el debate, 153-163. Lima: Universidad Peruana Cayetano Heredia.

Moles, Abraham \& Costa, Joan. (1999). Publicidad y diseño. Buenos Aires: Infinito.

Nieves, María Rico. (1996). Violencia de género: un problema de derechos humanos. S.L.: CEPAL.

Olsen, Frances. (1990). El sexo del derecho. En: Kairys, David (Ed.), The Politics of Law, 452-467. Nueva York: Pantheon. (Mariela Santoro y Christian Courtis, Trad.).

Organización de las Naciones Unidas. (2015, 9 de junio). Más del 80 por ciento de las personas con discapacidad son pobres, advierte la relatora de la ONU. Centro de Prensa de Naciones
Unidas. Recuperado de: http://www.un.org/spanish/News/story. asp?News ID=32551.

Palacios, Agustina. (2008). El modelo social de discapacidad: orígenes, caracterización y plasmación en la Convención Internacional sobre los Derechos de las Personas con Discapacidad. Madrid: CINCA. Recuperado de: https://www.cermi.es/sites/default/files/docs/ colecciones/Elmodelosocialdediscapacidad.pdf

Rodrigo Alsina, Miquel. (2005). La construcción de la noticia. Barcelona: Paidós.

Ruiz Bravo, Patricia. (2001). Sub-versiones masculinas. Imágenes del varón en la narrativa joven. Lima: Centro de la Mujer Peruana Flora Tristán.

Sala Civil de Cusco. (2019). Sentencia de 22 de mayo del 2019 recaída en el expediente 00798 -2014- 0-1001-JM-Cl-01.Disponible en: https://static.legis.pe/wp-content/uploads/ 2019/06 Exp.-00798-20141001-JM-CI-01-Legis.pe_.pdf?fbclid=IwAR28WEt4xBSB1K1eRIffiq Y1qvRt7363PABe3oVybyHObHzmitay0YVegnw

Serra, María Laura. (2016). Mujeres con discapacidad y situaciones de opresión deconstrucción feminista: desestabilizando las jerarquías de los dominios de poder. Tesis para obtener el grado académico de Doctora. Biblioteca de la Universidad Carlos III de Madrid. Recuperado de: http://hdl.handle.net/10016/24455

Stuart, Heather. (2006). Media Portrayal of Mental Illness and its Treatments: What Effect Does it Have on People with Mental Illness? CNS Drugs, 20(2), 99-106. Recuperado de: https://www.ncbi.nlm.nih. gov/pubmed/16478286

Tribunal de Ética para la Sociedad Nacional de Radio y Televisión - SNRTV. (2016). Resolución del 14 de abril de 2016 de queja por presunta infracción de los principios establecidos en la Ley de Radio y Televisión, el Código de Ética y el Pacto de Autorregulación, con relación a la edición del programa "Nunca Más".

Valega, Cristina (2019). ¿Des-Estereotipando el Derecho?: Análisis de la Interpretación de la regulación de la publicidad comercial realizada por el INDECOPI en casos de publicidad cuestionada por contener estereotipos de género considerados discriminatorios contra las mujeres. Tesis para obtener el título de abogada por la Pontificia Universidad Católica del Perú. Repositorio de Tesis PUCP. Recuperado de: http://hdl.handle.net/20.500.12404/14005

Valenciano Martínez - Orozco, Elena. (2004) Informe sobre la situación de las mujeres de los grupos minoritarios en la Unión Europea (2003/2109(INI)). Documento del Parlamento Europeo. A5-0102/2004.

Zambrano, Gustavo \& Uchuypoma, Diego. (2015). Intersectando desigualdades. Participación política de mujeres indígenas a nivel subnacional en el Perú. Lima: IDEHPUCP. 